\title{
Understanding Climate Change Perception in Community-Based Management Contexts: Perspectives of Two Indigenous Communities
}

\author{
Dr. Pepa Ambrosio-Albala \\ Sustainability Research Institute-School of Earth and Environment, University of Leeds, Leeds, United Kingdom, \\ and Department of Agricultural Economics, Universidad de Córdoba, Cordoba, Spain \\ Dr. MARÍA MAR DElGADO-SERRANO \\ Department of Agricultural Economics, Universidad de Córdoba, Cordoba, Spain
}

(Manuscript received 8 May 2017, in final form 19 March 2018)

\begin{abstract}
Many natural resources around the world are managed by indigenous communities that are closely connected to nature and have nature-based livelihoods. These communities are particularly vulnerable to climate change and in need of adaptation strategies. Therefore, understanding how a community that is connected to nature perceives climate change is crucial. Some studies have shown that the capacity to respond to climate change vulnerability might be influenced by the social ties among community members. We used Q methodology to explore and compare climate change perceptions in two indigenous communities in Colombia and Mexico. Both of these communities are characterized by nature-based livelihoods, collective ownership of land, and community-based natural resource management. We analyzed their perception of climate change and nature, their preferred options for adaptation strategies, and the sources of information they trust. The perceptions that emerged were interpreted according to the four worldviews proposed by cultural theory. Overall, this research suggests that perceptions varied across and within local contexts, meaning that different ways of understanding and dealing with climate change coexist within the communities. The results showed that hierarchy and egalitarian worldviews (as described by cultural theory) are more common in both indigenous communities. The history and lived experiences of community-based management for both communities influence preferred adaptation options to cope with climate change.
\end{abstract}

\section{Introduction}

Current projections indicate that climate variability will increase the intensity and frequency of weather hazards (IPCC 2014). Climate change (CC) is projected to not only amplify existing risks, but also create new ones (IPCC 2014). Indigenous communities are home to nearly 370 million people worldwide (United Nations 2009). Most of these communities have strong attachments to their territory and livelihoods that depend on natural resources. These communities are key actors in the management of environmental challenges (Armitage 2005) such as CC; however, they are also among the most vulnerable (UNPFII 2008). Many indigenous communities have traditionally adapted to variations in their environment mainly by a combination

\footnotetext{
Corresponding author: Dr. Pepa Ambrosio-Albala, P.ambrosio-albala@ leeds.ac.uk
}

of traditional knowledge and learning processes and their social structures, institutions, and internal communal arrangements (van Aalst et al. 2008; Boillat and Berkes 2013).

Previous studies have demonstrated that the adaptive capacity to $\mathrm{CC}$ might be influenced by the networks of reciprocity and livelihood-based ties to the environment (Adger 2003). Social relations may enhance the ability to cope with weather-related and environmental hazards and to address the impacts of CC (Lorenzoni et al. 2007; Wolf et al. 2013). A good example of the above can be found in indigenous communities whose natural resources are collectively managed or who have close livelihood-based connections to natural resources (Chaudhary et al. 2012; Gruber 2011). It is, therefore, essential to comprehend the perceptions of people within the communities and to include them from the start when developing and designing CC adaptation strategies (UNPFII 2008) in a 
way that translates their capabilities into effective adaptation practices.

It is relevant to understand how community members explain and give meaning to environmental and climate changes, what these changes mean for them, and how the $\mathrm{CC}$ perceptions differ in each community. Few studies have addressed the CC perceptions in these communities. However, research on CC perceptions is essential for the design of CC adaptation actions (Roeser 2012; Stedman 2004). Additionally, this research can help anticipate and drive responses to risk events associated with $\mathrm{CC}$ and improve communication between policymakers and citizens (Zannakis et al. 2015).

The objective of this paper is to examine the perceptions of $\mathrm{CC}$ within two indigenous communities in Colombia and Mexico. The case studies were selected in the framework of a broad research project that aimed to identify sustainable governance models in the management of environmental challenges, most importantly CC. Both communities are characterized by strong livelihood-based ties to nature and systems of collective natural resource ownership and management. However, the communities differ in their history and governance rules. For example, community-based natural resource management strategies have been in place longer in the Mexican community, which also has greater autonomy from the national government than does the Colombian community. This research aims to understand the CC perceptions of indigenous communities and provide relevant information about their preferences for CC-related management and adaptation options. As in other studies (Weigle 2010), the findings of this research can support the design and implementation of $\mathrm{CC}$ adaptation strategies that will be accepted by local inhabitants.

We used $\mathrm{Q}$ methodology to analyze the community members' perceptions. This methodology helps to reveal different types of perceptions at play in a particular context and is a means of studying subjectivity through factor analysis (Brown 1992). Q methodology is also recognized as an appropriate tool for rural social research (Previte et al. 2007) and has been used in studies on CC risk perception and environment-related matters (Albizua and Zografos 2014; Bacher et al. 2014; Forrester et al. 2015). Few studies have used Q methodology with indigenous peoples in Latin America (Baur et al. 2014; Gruber 2011).

In this study, we used cultural theory (CT) and the four worldviews on environmental risk, myths of nature, risk, and decision -making processes and climate change policy to frame our interpretation of the perspectives that emerged in the analysis. The cultural theory rationale helps explain how people within the communities of our research understand CC according to their particular culture, values, and concerns (Douglas 1985). Using cultural theory to analyze the results of a $\mathrm{Q}$ methodology study represents an original and unique methodological contribution. This research is relevant and timely because both countries are expected to be highly affected by CC (IPCC 2014), are rich in natural resources (Myers et al. 2000), and have large areas that are collectively managed (Bello et al. 2014; Merino Perez and Martínez 2014). Similar situations exist in many other countries throughout the world.

\section{Applying cultural theory in climate change perception studies}

The factors that determine the vulnerability to and risks of CC are dynamic (Smit and Wandel 2006). Consequently, it is important to acknowledge the influences of the context and the cultural differences and views in any CC risk assessment. Neither the design of CC policies nor the communication of $\mathrm{CC}$ risk occurs in a social vacuum (Akerlof et al. 2013; Jones and Clark 2013). Understanding how worldviews affect CC perception is crucial for addressing and effectively communicating CC (Marris et al. 1998; Oltedal et al. 2004; Roeser 2012; Stedman 2004). Cultural theory aims to explain how people perceive and act about the world around them (Oltedal et al. 2004). The approach provides a basis for examining the cultural locations within which $\mathrm{CC}$ is conceptualized and offers a way to understand how worldviews, sociocultural factors, and personal experiences influence CC perceptions (Gierlach et al. 2010; McNeeley and Lazrus 2014). Therefore, cultural theory could support the inclusion of local and cultural differences in the design of CC adaptation strategies. Cultural theory has been proven to be useful for answering questions such as who is to be trusted to manage risk or who gets blamed in the case of disaster (Marris et al. 1996).

For CT, certain patterns of social relationships generate a specific way of looking at the world based on two dimensions of sociality: group and grid. The former dimension is the extent to which a person is incorporated and defined by the social collectivity (group), and the latter dimension is the degree to which external prescriptions circumscribe an individual (grid) (Douglas 1992). Since its original design (Douglas 1992), cultural theory has been revised to include economic spheres (Meader 2002) and has been applied in the domain of CC (Steg and Vlek 2009). Additionally, cultural theory has been used to examine the relationship between perception of environmental risk concern and preference for environmental management strategies (JenkinsSmith et al. 2014; Jenkins-Smith and Sabatier 1999). 
Four cultural types can be identified according to the degree of cohesion among group members and the distinction between them and "others" (Douglas 1992): egalitarianism, fatalism, hierarchy, and individualism. These dimensions give rise to four distinct cultural biases or worldviews on the socially constructed "myths of nature" (Dake 1992). These worldviews can also be translated into different perspectives on and responses to CC (Douglas and Wildavsky 1982; Meader 2002; Thompson 2003).

For individualists, nature is benign and resilient, and people's needs and resources can be managed with a rational strategy. Individualists have a low perception of environmental risk and are predisposed to perceiving $\mathrm{CC}$ as nonexistent. Individualists have a short-term view of the future and are opposed to narrow climate-specific policies, especially those involving government actions (Jenkins-Smith et al. 2014).

Within the hierarchy worldview, nature is perceived to be in unstable equilibrium. Hierarchists have respect for conventions and order and consider structured hierarchical management to be essential to respond to CC. A sound management strategy requires large-scale institutions and organizations to keep natural resources in an appropriate state (Jenkins-Smith et al. 2014).

Egalitarians are primarily concerned with social equity and environmental protection. For them, nature is fragile and ephemeral, and natural resources are limited (Thompson 2003). However, these resources are still considered to be sufficient if people in richer countries would reduce their uses. Egalitarians are inclined to perceive $\mathrm{CC}$ as a severe risk and are engaged in proenvironmental decisions and initiatives.

Last, fatalists do not take part in any political debate and doubt the benefit of cooperation. Fatalists do not have a preferred approach to environmental management because to them, humans and nature are "unpredictable" and "changeable." Fatalists rarely engage in the management of natural resources and are skeptical of the benefits of cooperating with others. For fatalists, there is no specific behavior or strategy for coping with environmental change and $\mathrm{CC}$ because nature is unpredictable (Meader 2002).

\section{Research sites}

a. Community Councils of Black Communities of Bajo Calima and Alto y Medio Dagua (Colombia) (Onward Community Councils)

In the Colombian case, we worked with two Community Councils of Black Communities in the municipality of Buenaventura. We treated these communities as a single case for sampling purposes. Both community councils are part of the megadiverse ecoregion of Chocó (Arbeláez-Cortés 2013) and cover approximately 78000 ha with 5650 inhabitants. The basis of their economy is the exploitation of forests, agriculture, artisanal mining, and fisheries. According to the Colombian classification of access to basic services and the daily income per capita, the population in this region belongs to the lowest strata (Farah et al. 2012). The Law 70/1993 and the Colombian Constitution granted Afrodescendant communities the collective property of the state lands, where they had traditionally lived in return for sustainable management. From that moment on, the community councils (community-based management structures) were officially recognized.

These communities have long histories of associativity but sometimes limited cohesion. In addition, the community councils of Dagua and Calima were officially recognized only in 2005 and 2008, respectively; thus, their collective management rules and institutions are relatively recent and in the process of implementation. As a result, the council authorities have natural resource access and usage rights but limited means to implement monitoring, exclusion, and enforcement rights; they require the support of state institutions for these tasks. Social sanctioning mechanisms exist, but the rules are not always respected.

In both councils, connection with nature is a central axis of community life and reinforces the territorial identity. However, as a result of limited economic opportunities, the livelihoods in the community are largely based on the exploitation of natural resources.

\section{b. Santiago Comaltepec (Mexico) (Onward Comaltepec)}

Santiago Comaltepec is a Chinantec indigenous community located in the Sierra Norte of Oaxaca (Mexico) in the Mesoamerican biocultural region. The area is known for the successful conservation of its forest (Chapela 2007), and it spans over 18300 ha and has 1115 inhabitants. Subsistence agriculture and communitymanaged logging support the economy. The community has a medium level of economic marginality, according to Mexican standards.

The community has collective land and forest property rights granted by the Agrarian Law of 1953. However, people have managed their lands according to a customary and community-based governance regime for centuries. The General Assembly of Commoners has autonomy to decide on issues affecting community life and forest management. Robust institutional arrangements to manage natural resources, including exclusion, monitoring, and enforcement rights, exist, and the rules 
are highly respected by community members and external stakeholders (Escalante Semerena et al. 2012). The decisions of the assembly are always respected, and social sanctioning mechanisms are very effective at shaping community member behavior.

The community is highly cohesive with a strong attachment to nature and high environmental awareness. Only small portions of their forests are exploited commercially, leaving the rest under environmental protection schemes. This protection results in a limited availability of income sources, which pushes the younger generations and better-trained inhabitants to migrate.

\section{Methodology}

We used $\mathrm{Q}$ methodology to examine community member perceptions of $\mathrm{CC}$ and the meanings associated with it. Following McKeown and Thomas (2013), Q methodology was organized into five stages in this study: (i) generating and exploring the statement set, (ii) selecting people, (iii) Q sorting, (iv) analyzing the data, and (v) interpreting the results. A description of this technique can be found in Watts and Stenner (2012).

\section{a. Generating the statement set}

The first step was to explore the concourse (opinions and views about a particular topic of interest) and to generate a series of statements related to the topic. The statement set can emerge from personal interviews with respondents. However, the statement set can also be developed from relevant secondary sources. As in other studies (Barry and Proops 1999; McKeown and Thomas 2013), our concourse was generated from secondary sources. This method allows for comparisons between case studies and tends to be the preferred option for cross-cultural and cross-national studies (Robyn 2005). We used existing research studies on CC and environmental issues (Barry and Proops 1999; Dunlap et al. 2000; Leiserowitz 2007; Niemeyer et al. 2005; Wolf 2005) to develop the statement set. Further, to ensure that the selection of the statements reflected the reality of the communities, we used our prior experiences of work in the territories (e.g., the analysis of issues related to how communities face environmental challenges) and involved local researchers with a long tradition of work and good reputation among the communities. We selected statements related to the issues we were interested in analyzing: (i) vision of nature (i.e., perspective on the environment), (ii) concern and responsibility over $\mathrm{CC}$, (iii) impacts of CC, (iv) information sources (i.e., trust in information sources), and (v) environmental management (i.e., management of CC-related environmental issues). A total of 41 statements formed the final statement set (Table 1). The statements were included as in the original English sources, but with some adaptations for context. To compare and contrast the results, we translated the statements into Spanish, and native researchers proofread and adjusted the vocabulary to each local context and corroborated that the statements could be used in both cases. While specific words were tailored to each statement set, the complete Q sample was developed from the same base set of secondary-source statements.

\section{b. Selecting participants}

In $\mathrm{Q}$ methodology, a large number of participants is not required to explicate and compare viewpoints. Kline's rule establishes a minimum ratio of one participant to every two statements to determine the number of respondents [Kline (1994), as cited in Watts and Stenner (2012)]. In our study, the minimum number of respondents for each case study was 20. A total of 23 participants (15 female and eight male) and 21 participants ( 3 female and 17 male; one participant preferred for their gender to not be mentioned) were selected for the Colombian and Mexican cases, respectively. The participants were chosen through stakeholder mapping techniques. The selection criteria were their links to natural resource management and their knowledge of the territory. We also sought as much diversity in age and gender as possible. The sample included inhabitants affiliated with the community, including local authorities and community leaders, natural resource managers, farmers, environmental guides, and locally based researchers (five for community councils and three in Comaltepec).

\section{c. $Q$ sorting}

The sorting was conducted face to face. The statements were provided to participants on separate numbered cards, along with a $\mathrm{Q}$ sort sheet that included instructions. The cards were shuffled before they were given to the participants. Each participant was initially asked to sort the items into three piles (mostly agree, mostly disagree, and neutral/uncertain positions). Next, they sorted the items in a more detailed way using a scale ranging from -4 (strongly disagree) to +4 (strongly agree). Respondents distributed their answers according to a forced-choice frequency distribution (Watts and Stenner 2012), writing the statement number in each blank cell. After scoring the statements, participants were asked to comment on the research topic and the method that was used. 
TABLE 1. Rotated factor matrix for Community Councils. Asterisk $(*)$ indicate those persons associated with a particular factor significant at $p<0.01$.

\begin{tabular}{lrrr}
\hline \hline Participant & Factor 1 & Factor 2 & Factor 3 \\
\hline 2 & $0.5118^{*}$ & 0.3092 & 0.3962 \\
7 & $0.7442^{*}$ & 0.0984 & -0.0913 \\
8 & $0.5341^{*}$ & 0.0046 & 0.3827 \\
10 & $0.6761^{*}$ & 0.1844 & 0.0989 \\
13 & $0.4676^{*}$ & 0.1184 & 0.2688 \\
14 & $0.7776^{*}$ & 0.0232 & -0.0035 \\
17 & $0.7148^{*}$ & 0.0028 & 0.3635 \\
18 & $0.6927^{*}$ & 0.1969 & 0.3389 \\
20 & $0.5917^{*}$ & 0.3972 & 0.3381 \\
22 & $0.6393^{*}$ & 0.4832 & 0.2675 \\
23 & $0.7291^{*}$ & 0.2103 & 0.0830 \\
9 & 0.1643 & $0.6999^{*}$ & -0.2658 \\
12 & 0.3938 & $0.6865^{*}$ & 0.2630 \\
15 & -0.0175 & $0.6761^{*}$ & 0.3086 \\
19 & -0.0404 & $0.5946^{*}$ & 0.2288 \\
21 & 0.0742 & $0.5462^{*}$ & -0.0776 \\
3 & 0.3422 & 0.2225 & $0.7078^{*}$ \\
4 & -0.0233 & 0.0805 & $0.8736^{*}$ \\
5 & 0.4124 & -0.0373 & $0.4973^{*}$ \\
Confounded Q sorts & & & \\
1 & 0.4789 & 0.4299 & 0.3894 \\
6 & 0.5587 & 0.5953 & 0.2697 \\
11 & 0.4905 & 0.4895 & 0.0081 \\
16 & 0.4852 & 0.4515 & 0.1332 \\
Total defining Q sorts & 11 & 5 & 3 \\
$\%$ expl. var. & 27 & 16 & 13 \\
\hline
\end{tabular}

\section{d. Analyzing the data}

The data from each case (community) were analyzed separately per case study, including a total of $23 \mathrm{Q}$ sorts in the Colombian case and 21 for the Mexican case. Each Q sort represents a distinct viewpoint on CC. To analyze the data, we used PQMethod software (Schmolck and Atkinson 2002). The $Q$ sorts were intercorrelated and subjected to a by-person analysis for each case study. First, the software calculated a correlation matrix for each case study, representing the level of similarity of the participants' perceptions. The data were then factor analyzed using principal component analysis. During this process, the Q sorts that represented similar perceptions were grouped together and then formed a particular factor. We used three parameters to determine the appropriate number of components: 1) components with eigenvalues higher than 1 ;2) components with two or more significant $\mathrm{Q}$ sort loadings at $p<0.01$ (Q sort significance was calculated at \pm 0.40 or above) (Brown 2004); and 3) components meeting Humphrey's rule: "a factor is significant if the crossproduct of its two highest loadings (ignoring the sign) exceeds twice the standard error..." (Brown 1980).
Three factors were extracted and varimax rotated for each of the case studies following Brown $(1980,2004)$ and Watts and Stenner (2012).

\section{e. Interpreting the results}

To interpret the results, attention was given to statements that were significant at $p<0.05$ and $p<.01$, to statements ranked as neutral, and to those ranked at +4 and -4 for each factor. In addition, we identified the perspectives shared by all participants through those statements ranked in a similar manner (consensus statements). The Q sorts that loaded significantly on a particular factor represented analogous viewpoints about CC. To develop the narratives of each perception type, the preliminary data analysis was done by letting the data talk by itself. In a second step, we used cultural theory rationale to structure our interpretations of the results.

\section{Results}

The results are summarized in Figs. 1 and 2 for Community Councils and Comaltepec, respectively. The figures include the demographic profile, and the cultural type is marked in italics where applicable. In addition, we include the consensus areas identified by the participants. Following other examples (Bacher et al. 2014), each perception was identified by each case study, followed by a number and a name. For each case study, we selected the statements correlated with each factor; Tables 1 and 2 show the participants who defined and shared a perception (factor), and Table 3 shows the factor arrays per community and the statement positions within the factor.

\section{a. Community Councils}

Nineteen of the $23 \mathrm{Q}$ sorts loaded significantly on one or more of the three extracted factors, explaining $56 \%$ of the study variance $(27 \%, 16 \%$, and $13 \%$ of the variance was explained for factors 1,2 , and 3 , respectively). The eigenvalues for factors 1,2 , and 3 were 9.1047, 1.9989, and 1.6728 , respectively. Correlations between factor scores are shown in Table 4. We found four participants whose perceptions loaded significantly on two different factors (confounding Q sorts); these participants were excluded from the construction of the final factors, as suggested by Brown (1992).

\section{1) COMmunity COUncil 1: CARING FOR NATURE}

Eleven participants are significantly associated with this factor. This perception is characterized by an ecocentric vision of nature (S15) and a strong concern about the environment (S40). For these participants, natural resources are limited (S34) and fragile (S36). According 


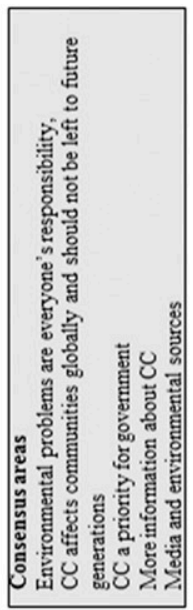

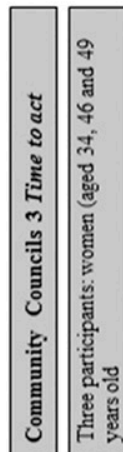
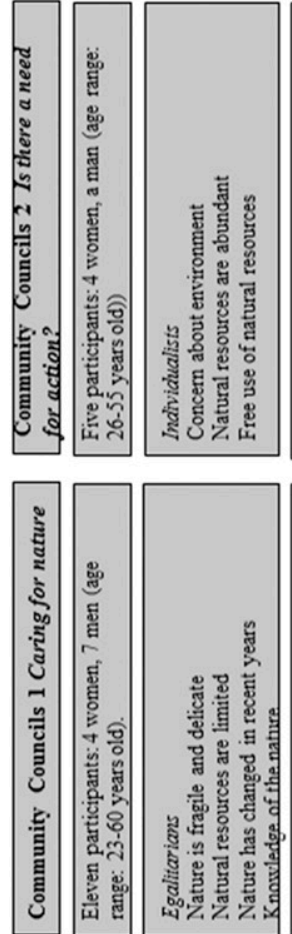

a.ṃฺe $\mathrm{N}$

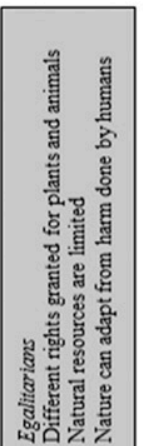

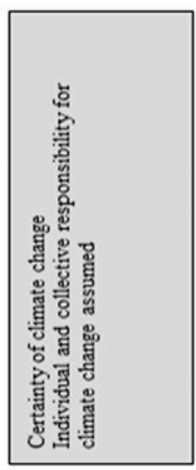
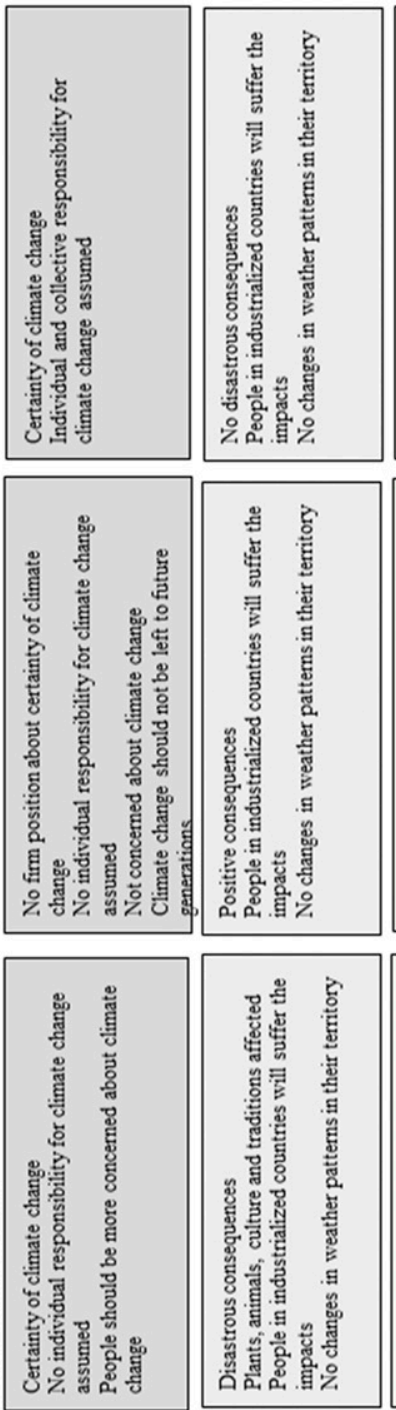

Ḳฺ!̣!q!suodsa. pur uəou⿰冫

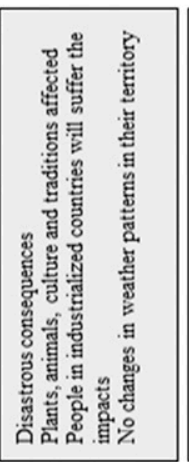

sิวeduI
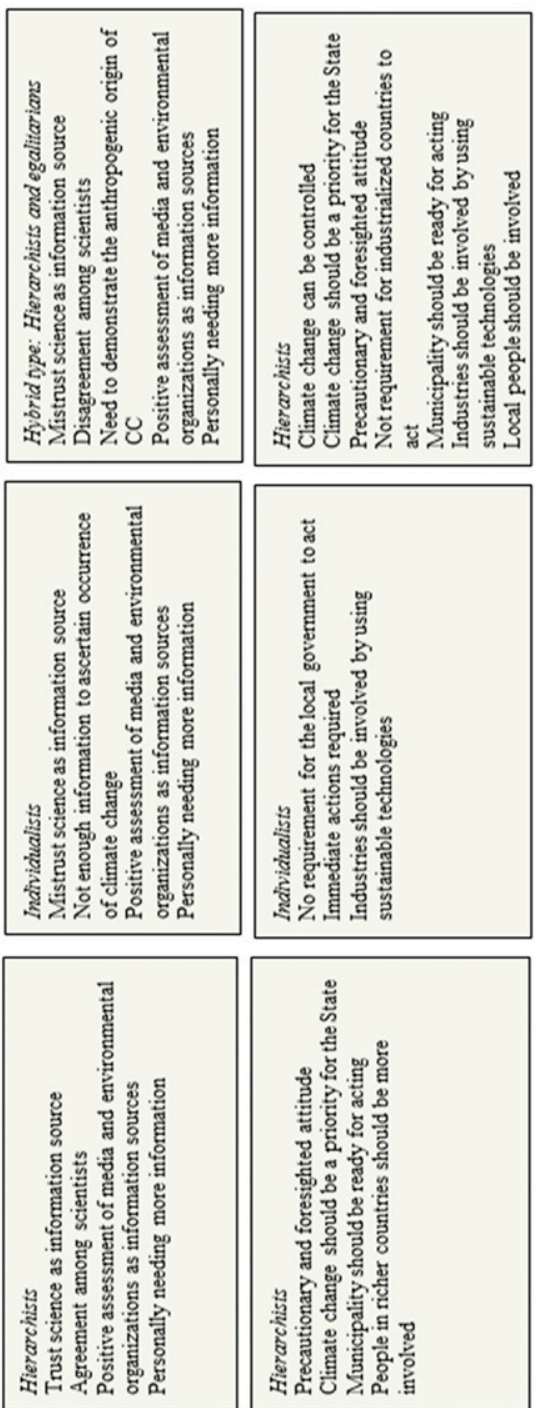

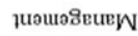



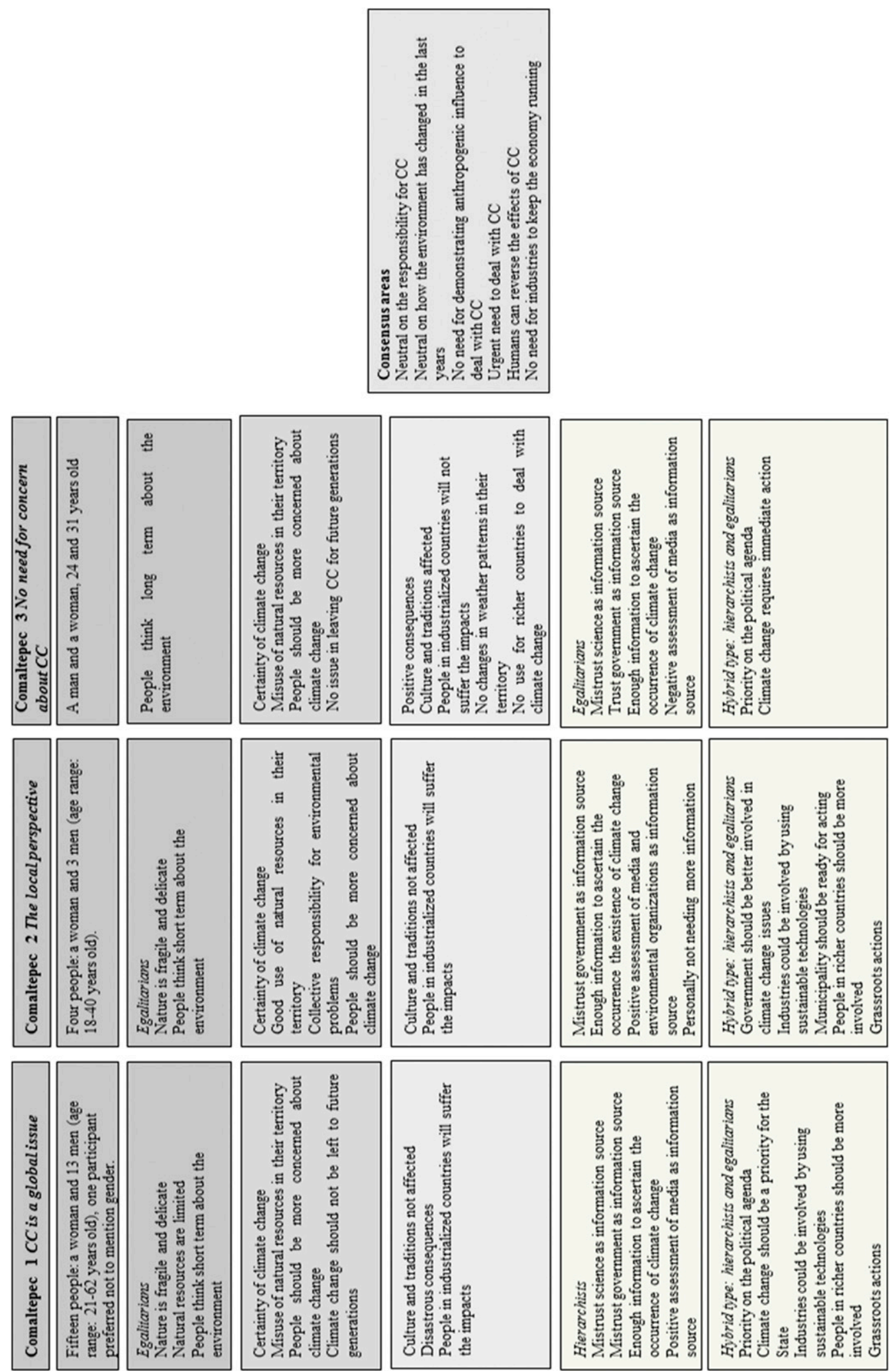

פ.mฺ̨eN

Кฺ̣!เฺ̣เsuodsa. pur แேวงกว

şฺвduI

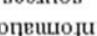

ไนวแวริยนะพ 
TABLE 2. Rotated factor matrix for Santiago Comaltepec. Asterisks $(*)$ indicate those persons associated with a particular factor significant at $p<0.01$.

\begin{tabular}{lrrr}
\hline \hline Participant & Factor 1 & Factor 2 & Factor 3 \\
\hline 1 & $0.8336^{*}$ & 0.1062 & 0.0778 \\
2 & $0.7033^{*}$ & 0.2860 & 0.1732 \\
3 & $0.8475^{*}$ & -0.0737 & -0.1217 \\
5 & $0.7179^{*}$ & 0.2966 & 0.0952 \\
6 & $0.5188^{*}$ & 0.4310 & 0.2019 \\
8 & $0.6786^{*}$ & 0.1946 & 0.3366 \\
9 & $0.5879^{*}$ & 0.2714 & -0.1994 \\
10 & $0.6238^{*}$ & 0.2157 & 0.0804 \\
11 & $0.4821^{*}$ & 0.3890 & 0.3109 \\
13 & $0.7395^{*}$ & 0.1016 & 0.0756 \\
15 & $0.7520^{*}$ & 0.1805 & 0.0710 \\
16 & $0.7086^{*}$ & 0.4870 & 0.0242 \\
17 & $0.6182^{*}$ & 0.5006 & 0.0236 \\
18 & $0.6626^{*}$ & 0.4662 & 0.1189 \\
20 & $0.6632^{*}$ & 0.5347 & 0.0367 \\
4 & 0.3376 & $0.4848 *$ & 0.3309 \\
7 & 0.5252 & $0.6022^{*}$ & -0.0204 \\
12 & 0.1055 & $0.6829 *$ & 0.1707 \\
14 & 0.0793 & $0.7950^{*}$ & -0.2343 \\
19 & 0.1004 & 0.4747 & $0.5756 *$ \\
21 & -0.0152 & -0.1268 & $0.8279 *$ \\
Total defining Q sorts & 15 & 4 & 2 \\
$\%$ expl. var. & 35 & 17 & 8 \\
\hline
\end{tabular}

to these participants, a change in the environment can negatively impact the community (S23). People holding this view acknowledge the importance of $\mathrm{CC}$ (S39) and firmly believe there is enough information to assert that $\mathrm{CC}$ is real (S14). People with this perception claim that CC can have very negative impacts (S29) on the community (S11) and worldwide (S10). As a community, they are concerned with environmental problems and believe that people should feel concerned about CC (S20). These participants demand the involvement of industrialized countries in dealing with CC (S37), but the roles and participation of private industries are not very clear to them (S41).

One participant from the community council stated, "This [exercise] helps me realize about the effect of human acts on the environment and how little we do to control it" (Participant 23).

\section{2) COMmunity COUncil 2: Is THERE A NEED FOR ACTION?}

Four women and one man represent this viewpoint. People holding this view are concerned about the environment (S40), strongly agree that people do not think long term about their actions (S6), and believe that plants, animals, and humans have the same rights to exist (S15). These participants do not feel responsible for contributing to $\mathrm{CC}$ (S1) and reject the idea that weather patterns have changed in their territory (S17).
Additionally, they mistrust scientific information about $\mathrm{CC}$ (S14, S32). They believe that CC may bring positive consequences to their territory (S11), but at the same time, they feel the need to stop CC to save ecosystems (S2). Therefore, from their perspective, there is no need for the local government to protect their territory from the effects of CC (S4), and it is not necessary to act before something occurs (S24). This result appears to contradict their views that a lack of action might create problems (S29), and people should be concerned about $\mathrm{CC}$ issues (S20). Overall, these participants believe CC should be a priority for the government (S18). Moreover, they consider that a change should occur regardless of what the government does (S27), and CC should be addressed now (S12).

\section{3) Community Council 3: Time to ACT}

Three women are associated with this perception. These participants believe that humans have different rights from plants and animals (S15). They recognize collective responsibility for environmental problems (S35, S1) and a collective obligation to address CC (S27, S37). Central to this perception is that humans should feel more concerned about $\mathrm{CC}$, regardless of if they can control it (S20), and that actions should occur sooner rather than later (S27). These participants demonstrate a preventive attitude (S24) to avoid disastrous consequences to ecosystems, culture, traditions (S2, S23, S29), and the community (S11). Because they believe that nature can recover from any damage caused by people (S36), it is not necessary to prioritize CC on the political agenda (S18), although it is wise to have a cautious attitude (S24). Despite not seeing changes in their territory (S17), they think that local people and the government should be better involved with $\mathrm{CC}$ issues (S13, S4). For them, the role of science and scientists is called into question (S19, S32). Even though they think there is enough information to state that CC is real (S14), they believe they still need more information (S9).

The consensus areas show that environmental problems are everyone's responsibility and that $\mathrm{CC}$ affects communities globally and should not be left to future generations. According to community councils, the government must prioritize $\mathrm{CC}$ in their agenda and assume these duties through legislation. People recognize the need to receive more information about $\mathrm{CC}$ from environmental organizations or the media since the government is not a trustworthy source of information. We found some inconsistencies within the Colombian community: for example, in relation to information sources, as the roles of scientists were mistrusted by one of the perception types. Also, there is no clear position on whether it is better to have a preventive attitude in 
TABLE 3. Factors arrays, distinguishing statements for factors and factor scores. Asterisk $(*)$ indicates significance level at $p<0.01$.

\begin{tabular}{|c|c|c|c|c|c|c|c|}
\hline \multirow[b]{2}{*}{ Statement } & \multirow[b]{2}{*}{ Factor arrays } & \multicolumn{3}{|c|}{$\begin{array}{l}\text { Community } \\
\text { councils }\end{array}$} & \multicolumn{3}{|c|}{ Comaltepec } \\
\hline & & 1 & 2 & 3 & 1 & 2 & 3 \\
\hline S1 & I feel guilty about my contribution to CC. & 0 & 0 & $2 *$ & 1 & 0 & 1 \\
\hline S2 & We have to stop CC to save natural ecosystems. & 3 & 2 & 0 & 3 & 3 & 0 \\
\hline S3 & The media does a poor job at conveying the effect of $\mathrm{CC}$ to the public. & -1 & $0 *$ & -2 & $0 *$ & $-3^{*}$ & $4 *$ \\
\hline S4 & $\begin{array}{l}\text { When it comes to CC impacts here, municipality should be prepared to deal } \\
\text { with them. }\end{array}$ & 0 & 0 & $2 *$ & 1 & 3 & 2 \\
\hline S5 & More educational programs are needed to increase public awareness about CC. & 3 & 2 & 1 & $3 *$ & 0 & 0 \\
\hline S6 & $\begin{array}{l}\text { People are not thinking about the long-term effects of what they do on } \\
\text { the environment. }\end{array}$ & 0 & $4 *$ & -1 & $4 *$ & $1 *$ & $-4 *$ \\
\hline S7 & It is difficult to trust what comes out in the media on the issue of CC. & -1 & 0 & 0 & 0 & -1 & 2 \\
\hline S8 & I trust what I hear about CC from government. & -1 & -1 & -1 & -2 & -2 & $1 *$ \\
\hline S9 & I feel I need more information about CC. & 0 & 1 & 2 & 0 & -1 & 1 \\
\hline S10 & People in modern industrialized countries will not be harm by CC. & -2 & -3 & -2 & -2 & -4 & $3 *$ \\
\hline S11 & I think that $\mathrm{CC}$ will bring good things to my community. & -4 & $0 *$ & -3 & -3 & -3 & $2 *$ \\
\hline S12 & It is unfair to leave $\mathrm{CC}$ to be solved by future generations. & 2 & 3 & 3 & $4^{*}$ & $0^{*}$ & $-2 *$ \\
\hline S13 & Buying local products is a good way to care about the environment. & 0 & 0 & $3 *$ & -1 & $3^{*}$ & 0 \\
\hline S14 & There is not enough information to definitively say that CC is real. & -2 & $0 *$ & -3 & -2 & -2 & -4 \\
\hline S15 & Plants and animals have as much right as humans to exist. & $1 *$ & $3 *$ & $-1 *$ & 2 & 4 & 2 \\
\hline S16 & The government should have stopped CC from happening. & 0 & 1 & $-3^{*}$ & -1 & 0 & -1 \\
\hline S17 & Nowadays, in my territory rains are much stronger, and it rains more than years ago. & 0 & $-4^{*}$ & 0 & 0 & 0 & -2 \\
\hline S18 & I think CC should be a priority for our government. & 2 & 2 & 0 & 1 & $0 *$ & \\
\hline S19 & There is lots of disagreement among scientists about whether or not CC is happening. & -2 & -1 & $1 *$ & -1 & -2 & -2 \\
\hline S20 & $\begin{array}{l}\text { People do not need to feel more concerned about } \mathrm{CC} \text { issues as these are not under } \\
\text { their control. }\end{array}$ & -4 & $-1^{*}$ & -4 & -3 & -2 & -1 \\
\hline S21 & $\begin{array}{l}\text { The government should take responsibility for legislating on environmental issues a } \\
\text { great deal more than it does. }\end{array}$ & 1 & 1 & 1 & 0 & 2 & $-1 *$ \\
\hline S22 & $\begin{array}{l}\text { In my community, we know well the environment, and we know when nature does not } \\
\text { behave normally. }\end{array}$ & $1 *$ & -1 & -1 & -1 & 1 & 0 \\
\hline S23 & If the environment changed, culture and traditions would not be the same. & 2 & 1 & $-1 *$ & -1 & -1 & $3 *$ \\
\hline S24 & When it comes to changing climate, I would rather be safe than sorry. & $4 *$ & $-2 *$ & $1 *$ & 1 & 2 & 1 \\
\hline S25 & $\begin{array}{l}\text { When buying things I think of nature and the costs these products generated in the } \\
\text { environment. }\end{array}$ & 0 & $-3^{*}$ & 0 & 0 & 2 & 1 \\
\hline S26 & Only when people feel affected by CC will they act. & -2 & -1 & 0 & 2 & -4 & -3 \\
\hline S27 & We should wait for the government to act on CC. & -2 & -2 & -4 & $-3^{*}$ & -1 & -1 \\
\hline S28 & Before we do anything, it has to be proven that people cause CC. & -1 & -1 & $1 *$ & 0 & 1 & 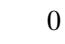 \\
\hline S29 & If we do not act now, $\mathrm{CC}$ will lead us to disaster. & 4 & 2 & $-1 *$ & 1 & 2 & 2 \\
\hline S30 & We need industries and fossil fuels to keep our economy running. & -3 & -2 & $1 *$ & -2 & -3 & -2 \\
\hline S31 & Environmental organizations scare the public with talk of CC. & -1 & -2 & 0 & -2 & -1 & -3 \\
\hline S32 & I trust what scientists say about $\mathrm{CC}$. & $1 *$ & -4 & -2 & -1 & 0 & -1 \\
\hline S33 & In my community, we sometimes misuse natural resources. & 1 & $0 *$ & 2 & $0^{*}$ & $-2 *$ & $4 *$ \\
\hline S34 & The Earth has plenty of natural resources if we just learn how to develop them. & -3 & $1 *$ & -2 & $-4 *$ & 0 & -1 \\
\hline S35 & We all have the responsibility for environmental problems. & 3 & 3 & 4 & 2 & $4 *$ & 0 \\
\hline S36 & Nature easily adapts and recovers from any damage caused by people. & -3 & -3 & $0^{*}$ & $-4 *$ & -1 & -2 \\
\hline S37 & $\begin{array}{l}\text { If people in richer countries around the world would take action to save energy, } \\
\text { we will reduce } \mathrm{CC} \text { a lot. }\end{array}$ & 2 & $-2 *$ & 0 & 1 & 2 & $-3 *$ \\
\hline S38 & The environment in my community has changed considerably over recent years. & $1 *$ & 0 & -2 & 0 & 0 & 1 \\
\hline S39 & $\mathrm{CC}$ is an important environmental issue. & $0 *$ & 2 & 2 & 3 & 1 & \\
\hline S40 & I am very concerned about the environment. & 2 & $4^{*}$ & 2 & 2 & 1 & -1 \\
\hline S41 & Industries should use new technology to become more efficient and help stop CC. & $-1^{*}$ & $1^{*}$ & $4 *$ & 2 & 1 & 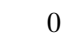 \\
\hline
\end{tabular}

regard to $\mathrm{CC}$ or if a change in behavior from people in industrialized countries could slow the effects of CC.

\section{b. Santiago Comaltepec}

All 21 Q sorts loaded significantly on one of the three extracted factors, accounting for $60 \%$ of the total explained variance of the study (factors 1,2 , and 3 adding $35 \%, 17 \%$, and $8 \%$ to the total explained variance, respectively). Table 5 shows correlation between factor scores. The eigenvalues were 9.6530, 1.6395 , and 1.3683 for factors 1,2 , and 3, respectively. Figure 2 shows the results, the most important aspects 
TABLE 4. Correlations between factor scores for the Community Councils.

\begin{tabular}{rccc}
\hline \hline & $\begin{array}{c}\text { Community } \\
\text { Council 1 }\end{array}$ & $\begin{array}{c}\text { Community } \\
\text { Council 2 }\end{array}$ & $\begin{array}{c}\text { Community } \\
\text { Council 3 }\end{array}$ \\
\hline $\begin{array}{r}\text { Community } \\
\text { Council 1 }\end{array}$ & 1 & & \\
$\begin{array}{r}\text { Community } \\
\text { Council 2 }\end{array}$ & 0.4572 & 1 & \\
$\begin{array}{r}\text { Community } \\
\text { Council 3 }\end{array}$ & 0.3877 & 0.2399 & 1 \\
\hline
\end{tabular}

characterizing the three perception types, and the consensus area.

\section{1) Comaltepec 1: CC is A Global issue}

The first factor represents the views of 15 people. Participants whose perceptions load significantly on this factor acknowledge that nature is fragile (S36), so humans should learn how to use it wisely (S34). This perception is consistent with the egalitarianism worldview. However, these participants recognize that natural resources in their territory are sometimes misused (S33) and that people think in the short term about their actions (S6). Respondents acknowledge $\mathrm{CC}$ as a major environmental issue (S39). Although these respondents believe that CC will not affect local culture and traditions (S23), they believe that $\mathrm{CC}$ could have disastrous consequences for their territory (S29) that should not be left to future generations (S12). Therefore, there should be more proactive participation and involvement of the government in CC and environmental issues (S18). This matter should be a priority on the political agenda (S21) and should be approached globally (S37), for example, by governments and people in richer countries but not exclusively by the government (S27). They do not perceive disagreement among scientists about CC (S19) and positively value the role of the media in communicating about $\mathrm{CC}(\mathrm{S} 3)$.

One of the community members of Comaltepec holding this perception stated, "It is necessary to enhance the culture of not littering anywhere and to save water" (Participant 10).

\section{2) Comaltepec 2: The local Perspective}

Four people held this perception in the Mexican community, acknowledging a shared responsibility for environmental issues. This perception type is characterized by an ecocentric vision of nature, namely, plants and animals having the same rights as humans (S15). These respondents agree that environmental problems are a matter of global concern (S35), with CC being a global matter (S10), and admit that people think shortsightedly about the consequences of their attitudes toward the environment (S6). These respondents feel
TABLE 5. Correlations between factor scores for Santiago Comaltepec.

\begin{tabular}{lccc}
\hline & Comaltepec 1 & Comaltepec 2 & Comaltepec 3 \\
\hline Comaltepec 1 & 1 & & \\
Comaltepec 2 & 0.5449 & 1 & \\
Comaltepec 3 & 0.1034 & 0.0470 & 1 \\
\hline
\end{tabular}

neutral about $\mathrm{CC}$ being a priority for the government (S18). However, they demand more responsibility from the government (S21), people from industrialized countries (S37), and local organizations (S13) for tackling $\mathrm{CC}$ and environmental problems. This contrasts with the idea that they are neutral about leaving CC to be addressed by future generations (S12); they reject the impact of CC on traditions and culture (S23). People with this viewpoint are satisfied with the level of information they have about CC (S9) and how the media and environmental organizations convey and communicate messages about CC (S3, S31).

One of the community members stated, "This exercise helps me realize how separated we are from climate change" (Participant 7).

\section{3) COMAltePec 3: No NeED FOR CONCERN ABOUT CC}

One man and one woman are significantly associated with this factor. Although people holding this perception type believe that natural resources might be misused in the community (S33), they consider that people think long term about the consequences of their actions on the environment (S6). These respondents do not perceive changes in the weather patterns in their territory (S17), but they stress that there is enough information to declare that CC is real (S14). According to their views, any change in the environment could result in changes in culture (S23), but CC could have positive consequences for their community (S11). These respondents believe that there is no need to preserve the environment and the ecosystems or to address CC (S2) and that it is not a problem to leave CC to future generations (S12). This perception type reflects the notion that people in industrialized countries will not be affected by CC (S10) and also that a change in their behavior does not necessarily mean a decrease in the effect of CC (S37). Nevertheless, it is highlighted that $\mathrm{CC}$ should be on the political agenda (S18). According to them, the media does a poor and unreliable job of conveying and communicating CC information (S3, S7). Instead, they look favorably on what comes from the government (S8) and the role legislation plays in CC issues (S21).

The consensus areas corroborate that there is a neutral position regarding who is responsible for CC. People 
agree with the fact that the environment in the territory has changed in recent years and that it takes time for nature to recover from damage. The consensus areas highlight that there is no need to demonstrate that CC is induced by humans to address it. Moreover, humans could reverse and control the effects of CC. Within the community, there was disagreement about several issues: for example, the role of the media in communicating the effects of $\mathrm{CC}$ and whether tackling $\mathrm{CC}$ effects can be postponed.

\section{Discussion}

We discuss the perceptions of communities regarding three main issues, namely, the relation between $\mathrm{CC}$ and nature, the sources of information and trust, and the preferred management actions to cope with $\mathrm{CC}$, using the worldviews suggested by cultural theory as a reference to frame the interpretation of the results and to broaden the applicability of the results to similar contexts. We did not expect, however, that the factor narratives would match with any of the worldviews suggested by the theory (Douglas and Wildavsky 1982; Douglas 1992).

A closer look into the different perception types indicates that the emerged perceptions vary across and within the communities. Moreover, we found several inconsistencies within the perception types. In Community Council 2, the community members care about nature, but they have a cornucopian understanding of it. These members also believe that $\mathrm{CC}$ is a very important issue and that not acting against CC could have disastrous consequences. Surprisingly, for them, there is no need to apply a precautionary principle. Continuing with the Colombian community, the people adhering to the perception type of Community Council 3 consider that it is better to act to stop the effects of $\mathrm{CC}$ but that it still remains to be proven whether people are causing CC. Disagreement was also found within the Mexican community. For instance, Comaltepec perception 2 is composed of people who consider environmental issues to be important but feel neutral about $\mathrm{CC}$ being a priority for the government. Additionally, individuals in Comaltepec 3 have positive views about the consequences of CC. However, they believe that CC should be a priority for the government to address.

\section{a. Relationship with nature and climate change}

Participants in our study generally perceived nature as fragile and delicate and believed that natural resources are limited, with the exception of Community Council 3. This result is consistent with the aspects of the egalitarian worldview, as defined by Douglas (1992). The perceptions in both communities are influenced by the cultural context (Akerlof et al. 2013) and reflect the livelihood dependence and the cultural attachment to nature. For example, the majority of participants in this research believe that CC should be "stopped" to save ecosystems. We also found that one perception type aligned more with an individualistic worldview. This result reflected a more utilitarian view of natural resources. Other studies on CC in the contexts of collective and community action showed similar results in which the individualist cultural type was found to be a residual (Pendergraft 1998).

The results also show that most participants are certain that CC exists, even if they do not appreciate the changes in weather patterns in their territory. Most people believe that people in industrialized countries will also suffer from the main impacts of CC, whereas the Intergovernmental Panel on Climate Change (IPCC) reports warn of the dramatic consequences of CC in less-industrialized and emerging countries, including Mexico and Colombia. Several perceptions-for example, Comaltepec 3 and Community Council 2-reflect that CC will not necessarily entail disastrous consequences, nor will it affect individuals and livelihood options. Moreover, for some of them (Community Council 2 and Comaltepec 3), CC could even lead to positive consequences for their territories. Similar results were found by Norgaard (2011) and were reported in other studies in Latin America (Perez Conguache 2008; Ramos García et al. 2011). A further study could provide a deeper understanding of the nature of this positive evaluation of $\mathrm{CC}$ to understand whether the positive evaluation of CC is socially organized, (e.g., shaped by social norms and interactions and through socialization within the communities; Zeruvabel 2006), or if it refers to individual cognitive processes.

\section{b. Engaging communities in adaptation planning}

Information is a key element for coping with and adapting to CC (Archie et al. 2014), as it influences how people consider CC threats as objective risks. Most individuals in the communities do not see changes in their immediate environment, but they still assert that $\mathrm{CC}$ is real. However, it remains unclear whether participants in the study perceive $\mathrm{CC}$ as a threat to their livelihoods and their framework of traditional knowledge and beliefs. Further studies could address whether this perception might be shaped by factors, such as content and information sources, previous and preconceived knowledge, and beliefs, as suggested by previous research (Lorenzoni and Pidgeon 2006).

The findings show different perspectives related to information on $\mathrm{CC}$ and trust in information sources. 
However, there is a consensus on the acceptance of the media and environmental organizations as reliable CC information sources. People's social ties (connections maintained in their social circle) reflect the type of knowledge they have access to and the sources they use (Smith and Sharp 2012). Many indigenous collective natural resource management systems are characterized by dense local networks of interdependence, high expected levels of bonding social capital (Putnam 2000) and within-group cohesion (Thompson 2000), and limited compliance with external prescriptions. This expectation suggests that information sources should come from their immediate/local context to be trusted (Mwalukasa 2013; Smith and Sharp 2012). The relationships of trust and reciprocity among the community members are connected not only to the sense of belonging to the group, but also to how people organize to connect with external actors such as external organizations (Merino Perez 1999; Merino Perez and Martínez 2014). In both case studies, members of both communities have a relationship of trust with some locally active environmental nongovernmental organizations (NGOs) and have traditionally relied on them to support several processes and procedures at the community. As for other indigenous communities, environmental organizations can play a major role in increasing the level of concern and awareness of $\mathrm{CC}$ and influencing the acceptability and even success of coping strategies proposed by the government and scientists.

A major issue found in this study is that four out of six perception types (two for each case study) indicated mistrust in science as a source of information. Previous research found that information can sometimes be ineffective because it does not convey what matters to the audience (McNeeley and Lazrus 2014). More broadly, contextually communicating and adapting CC information in ways that speak to local perspectives and idiosyncrasies remains a challenge. The scientific community should concentrate its efforts on delivering contextually sensitive CC information to indigenous communities. If the inclusion of indigenous communities in the CC conversation is to move forward, a better understanding of what $\mathrm{CC}$ means to those whose lifestyles and practices are connected to the environment needs to be developed.

\section{c. Adapting to climate change}

True to the sense of community and social organization in indigenous communities, no elements of individualism or fatalism were apparent in any of the perception types on how to adapt to CC. Rather, the preferred strategies to cope with $\mathrm{CC}$ align with hierarchical and egalitarian worldviews (Douglas 1992), that is, combining participatory models with national governmental regulations. The hierarchical worldview predominates in the community councils, while hybrid approaches between both types were found in all three perceptions in Comaltepec. These facts might be explained by the tradition of community-based management and the relations with the government institutions of both communities.

As described by cultural theory, for both hierarchy and egalitarianism worldviews, CC is a moral and ethical issue (Thompson 2003; Thompson et al. 1990). However, these worldviews differ in the accepted space for involvement of external institutions or actors (JenkinsSmith et al. 2014). Commonly, egalitarians would rely upon an individual's capacity to act independently (agency) within a group, while hierarchists would trust experts and knowledge to manage environmental issues (Jenkins-Smith et al. 2014). The results of this study support the statements formulated above. The community members in Colombia, where community-based actions are subject to external rules and the recognition of community management structures is relatively new, tend to prefer an active involvement of the government in dealing with CC. Analogous viewpoints have been found across indigenous communities in Colombia (Pinilla Herrera et al. 2012). In contrast, the Mexican community had greater autonomy to make their own decisions, combined with long-term experience in community-based management. This result could explain why the Mexican community relies on their capabilities to put CC adaptation strategies into practice and why their viewpoints reflect a demand for participation in CC adaptation management. Turner and Clifton (2009) found similar results in other indigenous communities.

The results suggest that the history and multilevel governance systems can shape whether people accept CC strategies and interventions from institutions outside of these communities. The implications of these results are not minor. These results corroborate that strategies to cope with CC should be context specific and prove that the implementation of these strategies without considering the needs, rights, and social dynamics of people would be an ill-advised decision (Hackmann and St. Clair 2012).

\section{Conclusions and recommendations}

In this study, we showed that CC perceptions are dynamic and context dependent. The social and cultural settings and the relation with natural resources and their management strategies can influence the 
shaping of CC perceptions in communities. We have corroborated that communities differ in their perceptions of nature and the CC-related issues that were analyzed in this research. However, we found that the predominant cultural types across the communities were hierarchy and egalitarianism. The rationale behind these two types aligns with the principles of the community-based management strategies (e.g., trust building and reciprocity, equity, community sense of belonging, and collective governance system). Moreover, we found that across the communities, community members expect top-down CC adaptation strategies, but at the same time, some of them demand to be included in the CC conversation (e.g., grassroots actions).

This research sets a positive precondition that could be used to enhance the ability of communities similar to those in this study to cope and adapt to CC. Joining the local knowledge, capabilities, and, most importantly, their understanding of $\mathrm{CC}$ in the communities with top-down CC policy actions could result in higher acceptance of the policies by these communities. Simultaneously, there is a need to generate communication strategies that are sensitive to the CC context and aimed at these communities. These communication strategies should come from both the scientific and the policy spheres. NGOs and civil society organizations (CSOs) rooted in the communities could play a major role in engaging them in both the policy-making and communication processes.

Combining both Q methodology and cultural theory provided a useful tool to identify differences and similarities of CC perceptions across and within the communities, based on different systems of beliefs and worldviews. As shown in the quotations, the process fostered reflection that increased their awareness about the environmental situation, the necessary actions, and the role they could play in CC adaptation. This study also applied cultural theory in a context that was different from where it was originally conceived. We used cultural theory as an instrument to explain whether different ways of managing natural resources and understanding social relations could explain different perceptions of CC. In relation to cultural theory, this research suggests that (i) people can hold different worldviews in different situations (Oltedal et al. 2004) and (ii) cultural types are not clearly distinguishable, (Douglas 1992) but rather complement each other (McNeeley and Lazrus 2014). More research should be conducted to continue the examination of cultural theory as a valid theoretical framework that can be used in contexts other than Western societies, beyond survey designs, and as a tool to explore cultural differences.
Acknowledgments. This research was funded by the Seventh Framework Programme of the European Commission in the frame of the project "Communitybased management of environmental challenges in Latin America" (FP7-ENV2011-282845 COMET-LA). The authors gratefully acknowledge the people from Community Councils of the Black Communities of Bajo Calima and Alto y Medio Dagua (Colombia) and Santiago Comaltepec (Mexico) who kindly participated and collaborated in the fieldwork of this research. The authors thank the reviewers for the comments and suggestions.

\section{REFERENCES}

Adger, W. N., 2003: Social capital, collective action, and adaptation to climate change. Econ. Geogr., 79, 387-404, https://doi.org/ 10.1111/j.1944-8287.2003.tb00220.x.

Akerlof, K., E. W. Maibach, D. Fitzgerald, A. Y. Cedeno, and A. Neuman, 2013: Do people "personally experience" global warming, and if so how, and does it matter? Global Environ. Change, 23, 81-91, https://doi.org/10.1016/j.gloenvcha.2012. 07.006 .

Albizua, A., and C. Zografos, 2014: A values-based approach to vulnerability and adaptation to climate change. Applying Q methodology in the Ebro Delta, Spain. Environ. Policy Gov., 24, 405-422, https://doi.org/10.1002/eet.1658.

Arbeláez-Cortés, E., 2013: Knowledge of Colombian biodiversity: Published and indexed. Biodivers. Conserv., 22, 2875-2906, https://doi.org/10.1007/s10531-013-0560-y.

Archie, K. M., L. Dilling, J. B. Milford, and F. C. Pampel, 2014: Unpacking the "information barrier": Comparing perspectives on information as a barrier to climate change adaptation in the interior mountain West. J. Environ. Manage., 133, 397410, https://doi.org/10.1016/j.jenvman.2013.12.015.

Armitage, D., 2005: Adaptive capacity and community-based natural resource management. Environ. Manage., 35, 703715, https://doi.org/10.1007/s00267-004-0076-z.

Bacher, K., A. Gordoa, and E. Mikkelsen, 2014: Stakeholders' perceptions of marine fish farming in Catalonia (Spain): A Q-methodology approach. Aquaculture, 424- 425, 78-85, https://doi.org/10.1016/j.aquaculture.2013.12.028.

Barry, J., and J. Proops, 1999: Seeking sustainability discourses with Q methodology. Ecol. Econ., 28, 337-345, https://doi.org/ 10.1016/S0921-8009(98)00053-6.

Baur, I., K. Liechti, and C. R. Binder, 2014: Why do individuals behave differently in commons dilemmas? The case of alpine farmers using common property pastures in Grindelwald, Switzerland. Int. J. Commons, 8, 657-685, https://doi.org/ 10.18352/ijc.469.

Bello, J. C., M. Báez, and M. Gómez, 2014: Biodiversidad 2014. Reporte de estado y tendencias de la biodiversidad continental de Colombia. Instituto Alexander von Humboldt Rep., 59 pp.

Boillat, S., and F. Berkes, 2013: Perception and interpretation of climate change among Quechua farmers of Bolivia: Indigenous knowledge as a resource for adaptive capacity. Ecol. Soc., 18, 21, https://doi.org/10.5751/ES-05894-180421.

Brown, M. M., 2004: Illuminating patterns of perception: An overview of Q methodology. Carnegie Mellon University, 
Software Engineering Measurement and Analysis Initiative Tech. Note CMU/SEI-2004-TN-026, 33 pp.

Brown, S. R., 1980: Political Subjectivity: Applications of $Q$ Methodology in Political Science. Yale University Press, $355 \mathrm{pp}$.

1992: Q methodology and quantum theory: Analogies and realities. Eighth Annual Conf. for the Scientific Study of Subjectivity, Columbia, MO, International Society for the Scientific Study of Subjectivity.

Chapela, F., 2007: El manejo forestal comunitario indígena en la Sierra de Juárez, Oaxaca. Los Bosques Comunitarios de México: Manejo Sustentable de Paisajes Forestales, D. Bray, L. Merino, and D. Barry, Eds., Instituto Nacional de Ecología, 123-145.

Chaudhary, P., K. Thapa, K. Lamsal, P. R. Tiwari, and N. Chhetri, 2012: Community-based climate change adaptation for building local resilience in the Himalayas. Human and Social Dimensions of Climate Change, N. Chhetri, Ed., InTech, 31-48, https://doi.org/10.5772/50608.

Dake, K., 1992: Myths of nature: Culture and the social construction of risk. J. Soc. Issues, 48, 21-37, https://doi.org/10.1111/ j.1540-4560.1992.tb01943.x.

Douglas, M., 1985: Risk Acceptability According to the Social Sciences. Russell Sage Foundation, 128 pp.

_ 1992: Risk and Blame: Essays in Cultural Theory. Routledge, 336 pp.

—, and A. Wildavsky, 1982: Risk and Culture: An Essay on the Selection of Technological and Environmental Dangers. University of California Press, $232 \mathrm{pp}$.

Dunlap, R. E., K. D. Van Liere, A. G. Mertig, and R. E. Jones, 2000: New trends in measuring environmental attitudes: Measuring endorsement of the new ecological paradigm: A revised NEP scale. J. Soc. Issues, 56, 425-442, https://doi.org/ 10.1111/0022-4537.00176.

Escalante Semerena, R. I., S. Basurto Hernández, S. I. Brugger Jakob, Y. Lara Padilla, F. Chapela, and I. H. López, 2012: Stakeholders' vision on the socio-ecological system (SES) situation in Mexico. A case study. Universidad Nacional Autónoma de México, Estudios Rurales y Asesoría Campesina Deliverable 3.1, $57 \mathrm{pp}$.

Farah, M. A., E. Garrido, D. L. Maya, C. Ortiz, and P. Ramos, 2012: Stakeholder vision on socio-ecological system situation in Colombia case study. Departamento de desarrollo Rural y Regional, Facultad de Estudios Ambientales y Rurales, Pontificia Universidad Javeriana Deliverable D2.1, 55 pp.

Forrester, J., B. Cook, L. Bracken, S. Cinderby, and A. Donaldson, 2015: Combining participatory mapping with Q-methodology to map stakeholder perceptions of complex environmental problems. Appl. Geogr., 56, 199-208, https://doi.org/10.1016/ j.apgeog.2014.11.019.

Gierlach, E., B. E. Belsher, and L. E. Beutler, 2010: Cross-cultural differences in risk perceptions of disasters. Risk Anal., 30, 1539-1549, https://doi.org/10.1111/j.1539-6924.2010.01451.x.

Gruber, J. S., 2011: Perspectives of effective and sustainable community-based natural resource management: An application of Q methodology to forest projects. Conserv. Soc., 9, 159-171, https://doi.org/10.4103/0972-4923.83725.

Hackmann, H., and A. L. St. Clair, 2012: Transformative cornerstones of social science research for global change. International Social Science Council Rep., 32 pp., http://go.nature.com/ 5MVqh1.

IPCC, 2014: Impacts, Adaptation, and Vulnerability. Part B: Regional Aspects. Cambridge University Press, 688 pp., http://www.ipcc.ch/ pdf/assessment-report/ar5/wg2/WGIIAR5-PartB_FINAL.pdf.
Jenkins-Smith, H. C., and P. A. Sabatier, 1999: The advocacy coalition framework: An assessment. Theories of the Policy Process, P. Sabatier, Ed., Westview Press, 117-166.

— C. Silva, J. T. Ripberger, and K. Gupta, 2014: Belief system continuity and change in policy advocacy coalitions: Using cultural theory to specify belief systems, coalitions, and sources of change. Policy Stud. J., 42, 484-508, https://doi.org/ 10.1111/psj.12071.

Jones, N., and J. Clark, 2013: Social capital and climate change mitigation in coastal areas: A review of current debates and identification of future research directions. Ocean Coastal Manage., 80, 12-19, https://doi.org/10.1016/j.ocecoaman. 2013.03.009.

Kline, P., 1994: An Easy Guide to Factor Analysis. Routledge, $194 \mathrm{pp}$.

Leiserowitz, A., 2007: Public perception, opinion and understanding of climate change: Current patterns, trends and limitations. Human Development Report Office Thematic Paper 2007/31, 40 pp.

Lorenzoni, I., and N. F. Pidgeon, 2006: Public views on climate change: European and USA perspectives. Climatic Change, 77, 73-95, https://doi.org/10.1007/s10584-006-9072-z.

_ S. Nicholson-Cole, and L. Whitmarsh, 2007: Barriers perceived to engaging with climate change among the UK public and their policy implications. Global Environ. Change, 17, 445-459, https://doi.org/10.1016/j.gloenvcha.2007.01.004.

Marris, C., I. H. Langford, and T. O'Riordan, 1996: Integrating sociological and psychological approaches to public perceptions of environmental risks: Detailed results from a questionnaire survey. CSERGE Working Paper GEC 96-07, $113 \mathrm{pp}$.

,-- , and -1998 : A quantitative test of the cultural theory of risk perceptions: Comparison with the psychometric paradigm. Risk Anal., 18, 635-647, https://doi.org/10.1023/B: RIAN.0000005937.60969.32.

McKeown, B., and D. B. Thomas, 2013: Q Methodology. SAGE Publications, $120 \mathrm{pp}$.

McNeeley, S. M., and H. Lazrus, 2014: The cultural theory of risk for climate change adaptation. Wea. Climate Soc., 6, 506-519, https://doi.org/10.1175/WCAS-D-13-00027.1.

Meader, N., 2002: A theoretical and methodological examination of cultural theory applied to environmental issues. Ph.D. thesis, University of Surrey, 266 pp., http://epubs.surrey.ac.uk/ 851/1/fulltext.pdf.

Merino Perez, L., 1999: La gestión colectiva de los recursos forestales. Revista Mexicana de Comercio Exterior, UNAM, Ciudad de Mexico, http://www.era-mx.org/publicaciones/ gestion.html.

_ - and A. E. Martínez, 2014: A Vuelo de Pájaro: Las Condiciones de las Comunidades con Bosques Templados en México. CONABIO, $188 \mathrm{pp}$.

Mwalukasa, N., 2013: Agricultural information sources used for climate change adaptation in Tanzania. Libr. Rev., 62, 266292, https://doi.org/10.1108/LR-12-2011-0096.

Myers, N., R. A. Mittermeier, C. G. Mittermeier, G. A. B. da Fonseca, and J. Kent, 2000: Biodiversity hotspots for conservation priorities. Nature, $\mathbf{4 0 3}, 853-858$, https://doi.org/10.1038/ 35002501 .

Niemeyer, S., J. Petts, and K. Hobson, 2005: Rapid climate change and society: Assessing responses and thresholds. Risk Anal., 25, 1443-1456, https://doi.org/10.1111/j.1539-6924.2005.00691.x.

Norgaard, K. M., 2011: Living in Denial: Climate Change, Emotions, and Everyday Life. MIT Press, 304 pp. 
Oltedal, S., B.-E. Moen, H. Klempe, and T. Rundmo, 2004: Explaining risk perception. An evaluation of cultural theory. Norwegian University of Science and Technology, Department of Psychology Rep., 46 pp., http://www.svt.ntnu.no/psy/ Torbjorn.Rundmo/Cultural_theory.pdf.

Pendergraft, C. A., 1998: Human dimensions of climate change: Cultural theory and collective action. Climatic Change, 39, 643-666, https://doi.org/10.1023/A:1005323809980.

Perez Conguache, A. F., 2008: Mujeres indígenas de Guatemala y sus percepciones sobre el cambio climático. Mujeres Indígenas y Cambio Climático. Perspectivas Latinoamericanas, A. Ulloa et al., Eds., UNAL-Fundación Natura de Colombia-UNODC, 61-65.

Pinilla Herrera, M. C., A. Rueda, C. Pinzon, and J. Sanchez, 2012: Percepciones sobre los fenómenos de variabilidad climática y cambio climático entre campesinos del centro de Santander, Colombia. Ambiente y Desarrollo, 16, 25-37.

Previte, J., B. Pini, and F. Haslam-McKenzie, 2007: Q methodology and rural research. Sociologia Ruralis, 47, 135-147, https:// doi.org/10.1111/j.1467-9523.2007.00433.x.

Putnam, R., 2000: Bowling Alone: The Collapse and Revival of American Community. Simon \& Schuster, 541 pp.

Ramos García, C., A. D. Secue, and F. Muñoz Yule, 2011: Ciclos naturales, ciclos culturales, percepción y conocimientos tradicionales de los nasas frente al cambio climático en Toribío, Cauca, Colombia. Perspectivas Culturales del Clima, A. Ulloa, Ed., Universidad Nacional de Colombia, 247-273.

Robyn, R., 2005: The Changing Face of European Identity. Routledge, $429 \mathrm{pp}$.

Roeser, S., 2012: Risk communication, public engagement, and climate change: A role for emotions. Risk Anal., 32, 10331040, https://doi.org/10.1111/j.1539-6924.2012.01812.x.

Schmolck, P., and J. Atkinson, 2002: The QMethod page. PQMethod, http://schmolck.userweb.mwn.de/qmethod/.

Smit, B., and J. Wandel, 2006: Adaptation, adaptive capacity and vulnerability. Global Environ. Change, 16, 282-292, https:// doi.org/10.1016/j.gloenvcha.2006.03.008.

Smith, H. A., and K. Sharp, 2012: Indigenous climate knowledges. Wiley Interdiscip. Rev.: Climate Change, 3, 467-476, https:// doi.org/10.1002/wcc. 185 .

Stedman, R. C., 2004: Risk and climate change: Perceptions of key policy actors in Canada. Risk Anal., 24, 1395-1406, https:// doi.org/10.1111/j.0272-4332.2004.00534.x.

Steg, L., and C. Vlek, 2009: Encouraging pro-environmental behaviour: An integrative review and research agenda. J. Environ. Psychol., 29, 309-317, https://doi.org/10.1016/ j.jenvp.2008.10.004.
Thompson, M., 2000: Understanding environmental values: A cultural theory approach. Carnegie Council for Ethics in International Affairs Rep., 10 pp., http://www.carnegiecouncil.org/ publications/articles_papers_reports/710.html.

_ 2003: Cultural theory, climate change and clumsiness. Econ. Political Wkly., 38, 5107-5112.

— R. J. Ellis, and A. Wildavsky, 1990: Cultural Theory. Westview Press, 296 pp.

Turner, N. J., and H. Clifton, 2009: "It's so different today": Climate change and indigenous lifeways in British Columbia, Canada. Global Environ. Change, 19, 180-190, https://doi.org/ 10.1016/j.gloenvcha.2009.01.005.

United Nations, 2009: State of the World's Indigenous Peoples. United Nations, 250 pp., http://www.un.org/esa/socdev/unpfii/ documents/SOWIP/en/SOWIP_web.pdf.

UNPFII, 2008: Climate change, bio-cultural diversity and livelihoods: The stewardship role of indigenous peoples and new challenges. Permanent Forum on Indigenous Issues' Seventh Session, New York, NY, United Nations, 24 pp.

van Aalst, M. K., T. Cannon, and I. Burton, 2008: Community level adaptation to climate change: The potential role of participatory community risk assessment. Global Environ. Change, 18, 165-179, https://doi.org/10.1016/j.gloenvcha.2007.06.002.

Watts, S., and P. Stenner, 2012: Doing Q Methodological Research: Theory, Method and Interpretation. SAGE Publications, $251 \mathrm{pp}$.

Weigle, J. L., 2010: Resilience, community, and perceptions of Marcellus Shale development in the Pennsylvania wilds. Ph.D. dissertation, The Pennsylvania State University, 255 pp., https://etda.libraries.psu.edu/files/final_submissions/ 2822.

Wolf, J., 2005: Individuals and climate change: Insights from a Q method study in Southern British Columbia. 21st Annual $Q$ Conference, Vancouver, Canada, International Society for the Scientific Study of Subjectivity, 15.

- I. Allice, and T. Bell, 2013: Values, climate change, and implications for adaptation: Evidence from two communities in Labrador, Canada. Global Environ. Change, 23, 548-562, https://doi.org/10.1016/j.gloenvcha.2012.11.007.

Zannakis, M., A. Wallin, and L.-O. Johansson, 2015: Political trust and perceptions of the quality of institutional arrangementsHow do they influence the public's acceptance of environmental rules? Environ. Policy Gov., 25, 424-438, https:// doi.org/10.1002/eet.1676.

Zeruvabel, E., 2006: The Elephant in the Room: Silence and Denial in Everyday Life. Oxford University Press, 177 pp. 